\title{
INTERRELATIONSHIPS EXISTING BETWEEN BODY WEIGHT AND EGG PRODUCTION TRAITS IN OLYMPIA BLACK LAYERS
}

\author{
C.A. CHINEKE \\ Department of Animal Production and Health, \\ Federal University of Technology, Akure \\ Received 10 May 1997; Accepted 25 November 1998
}

\begin{abstract}
Forty 76 weeks old Olympia Black layers were randomly selected, individually caged and intensively reared for a period of 16 weeks to study the effect of body weight on some egg production traits. The analysis of variance revealed significant effect of body weight on production traits investigated $(\mathbf{P}<0.01)$ except egg index $(\mathbf{P}>0.05)$. The correlation analysis showed that the body weight was positively and non-significantly (P>0.05) correlated with egg length, egg breadth, shell weight, yolk weight, albumen weight, shell thickness and significantly with egg weight, $(\mathbf{P}<0.01)$ and negatively with egg index $(r=0.016)$. The second-degree (quadratic) equations for estimates of optimum 76 week body weights suggested 1.271 to 1.801 as required body weight range in kilograms for satisfactory performance. The body weight range at this age is attainable through breeding, good feeding and other management practices.
\end{abstract}

Keywords: Olympia black layer, body weight, egg traits, second-degree equation, interrelationships.

\section{INTRODUCTION}

Body weight influence on quality traits is obvious. These traits and body weight contribute significantly to the life time performance of the animal. Researches conducted into relationships between body weight and quantitative traits are well observed for meat-type poultry (Draper et al., 1961; Ayeni et al., 1983; Monsi, 1992; Ebangi and Ibe, 1994; Ayorinde et al.,1994) and egg-type poultry (Omeje and Nwosu, 1984; Ayorinde et al.,1988; Oni et al.,1991 and Adenowo et $a l ., 1995)$. The functional relationships of the body weight to production traits need further clarification from breeders. The challenge before the breeders is therefore to develop the desired production traits especially high egg production and big body size (Ayorinde et al.,1988) using selection and breeding practices as tools. Such selection will mean selecting production traits that are highly and positively correlated and hence producing animals that are capable of high performance. Differences in performance brought about by non-genetic factors namely age, maternal effect, feeding, disease, management and climate cannot be overlooked. It is also note worthy that genetic factors show greatest influence. This explains the situation where within the same breed, strain or variety, individual variations in performance are common observations. Such individuals that are capable of high performance should be exploited in selection and breeding practices.

The paper reports on the association between body weight and some egg production traits in Olympia Black layers. It further attempts to predict performance from mature body weight using models or indices in the study.

\section{MATERIALS AND METHODS}

\section{Experimental Location and Bird Management}

The site of the experiment is the Teaching and Research Farm (poultry section) belonging to Federal University of Technology, Akure in Ondo State Nigeria. One thousand and fifty Olympia Black chicks were brooded on deep litter floor, with ad libitum foeding using commercial chick mash and regular water supply for the first five weeks. Medication and vaccination programmes were carefully 


\section{CHINEKE}

tollowed during brooding and rearing. At six weeks of age, the rationing of feed using commercial growers mash of $16 \%$ crude protein and $4.07 \mathrm{k} \mathrm{cal} / \mathrm{g} \mathrm{ME}$ started and continued until they were 16 weeks of age when some were transferred to battery cages. Each cage housed about three birds until they मere 75 weeks of age. At 75 weeks of age, 40 lavers were randomly selected from the cages and were housed individually per cage measuring $46 \times 39.3 \times 44 \mathrm{~cm}$. They were allowed to acclimatize for 5 days before data colkction which commenced when the birds attained 76 weeks of age. A commercial layers mash containing $90.95 \%$ dry matter, $9.05 \%$ ash, $16.85 \%$ crude protein, $4.80 \%$ fat, $3.98 \%$ crude fibre and $56.27 \%$ NFE was fed at $0.114 \mathrm{~kg}$ per hen per day, while water was supplied regularly throughout the 16 weeks experimental period.

\section{Data collection and statistical analyses}

The birds were weighed at the beginning of the experiment and at weekly intervals. Egg production of each layer was recorded from 76 weeks up to 91 weeks of age, and each egg collected was marked according to cage number and the production was summarized on weekly and individual basis. All eggs laid by each layer were weighed and their length and breadth measured using vernier calipers. Egg index was determined as the ratio of egg breadth to egg length. One egg randomly selected from the total weekly egg laid by each hen was carefully broken and the contents poured into standard egg separator. The albumen and yolk were separated and weighed using Ohaus Electronic scale. The shell weight was also taken. A micrometer screw gauge was used to determine the shell thickness.

Variations in each of the parameters due to body weight, were examined for statistical difference using the completely randomized design (Steel and Torrie, 1980). Correlations between the traits and body weight were computed using the Pearson Correlation Module according to Statistical Package for Social Science (1986) procedures. The associations between 76-week body weight and each trait was described by a quadratic equation following a polynomial distribution (Younger, 1985). The second-degree or quadratic equation used was $Y=a+b c+c x^{2}$ where the dependent variable $(y)=$ various egg traits; the independent variable $(x)=76$-week body weight; $a$ b and $c$ are numerical values or constants obtainable from the data so that the response variable or dependent variable $(y)$ can be predicted by simply substituting its size $(x)$ into the regression equation. The quadratic relationship analyses were used in attempts to disentangle and measure the effects of different $x$ - variables on some response $Y$ since in many areas of research, such as this study the controlled experiments are not practicable (Snedecor and Cochran, 1976).

The equations used are:

$$
\begin{array}{lll}
\Sigma Y_{i} & = & n a+b \Sigma X_{i}+c \Sigma X_{i}^{2} \\
\Sigma X_{i} Y_{i}= & a \Sigma X_{i}+b \Sigma X_{i}^{2}+c X \Sigma{ }_{i}{ }^{3} \\
\Sigma X_{i}{ }^{2} Y_{i}= & a \Sigma X_{i}{ }^{2}+b \Sigma X_{i}{ }^{3}+c \Sigma X_{i}^{4}
\end{array}
$$

The value of $X$ ( 76 week body weight) that will give the maximum value of each of the egg traits (y) was determined from the equation $X$ $\max =b / 2 c$ (Little and Hills, 1978).

\section{RESULTS AND DISCUSSION}

The population parameters are given in Table 1 . About 3016 eggs laid by the 40 layers over a period of 16 weeks were used to determine egg weight, egg length, egg breadth, egg index and hen-day production. While 640 eggs representing a total number of eggs randomly selected from weekly egg production of each layer were broken and used to determine albumen weight, shell weight, yolk weight and shell thickness. The first four weeks of the experiment recorded consistent increase in body weight gain attributable to increases in maintenance requirement. Its rising and falling in subsequent weeks probably resulted from body weight maintenance and egg formation processes sharing the available nutrient. Du plessis and Eramus (1972) and Ayorinde et al. 
BODY WEIGHT VS EGG PRODUCTION TRAITS IN OLYMPIA BLACK LAYERS

TABLE 1: EGG PRODUCTION TRAITS RECORDED ON FORTY OLYMPIA BLACK LAYING HENS

\begin{tabular}{llllll}
\hline Traits & $\begin{array}{l}\text { No of } \\
\text { Observations }\end{array}$ & Mean & $\begin{array}{l}\text { Standard } \\
\text { Error }\end{array}$ & Min & Max \\
\hline Egg length (cm) & 3106 & 6.24 & 0.0158 & 5.92 & 6.43 \\
Egg breadth (cm) & 3106 & 4.98 & 0.0122 & 4.43 & 4.83 \\
Egg index & 3106 & 0.763 & $3.589^{-03}$ & 0.71 & 0.81 \\
Egg weight (g) & 3106 & 63.06 & 0.1924 & 59.28 & 66.15 \\
Albumen weight (g) & 640 & 37.91 & 0.279 & 35.58 & 40.07 \\
Yolk weight (g) & 640 & 16.89 & 0.1202 & 16.51 & 17.66 \\
Shell weight (g) & 640 & 7.85 & 0.0538 & 7.45 & 8.35 \\
Shell thickness (mm) & 640 & 0.31 & $2.372^{-03}$ & 0.30 & 0.32 \\
Body weight (g) & 640 & 1726.25 & 6.275 & 12.71 & 18.01 \\
Hen-day (\%) & 3106 & 69.33 & 0.0893 & 61.07 & 76.79 \\
\hline
\end{tabular}

(1988) reported consistent reduction in body weight which they attributed to an increased use of physiological reserves to meet egg production demands.

There were observed increases in egg weight, length, breadth, albumen weight and hen-day production in the first three weeks. These were similar to those severally reported in literature (Gerstmayr and Horsi, 1990; Olori and Sonaiya, 1992; Austic and Nesheim, 1990; Asuquo, 1994).

These traits assumed rising and falling trend in subsequent weeks of the experiment. The egg index, shell weight, yolk weight and shell thickness maintained similar trends during the study period.

The mean squares and degree of freedom from analyses of variance for effect of body weight. on egg production traits are presented in Table 2. The body weight exerted significant influence on production traits investigated $(\mathrm{P}<0.01)$ except egg index $(\mathrm{P}>0.05)$. These were in line with research findings published in literature (Ricklefs, 1983; Ayorinde et al., 1988).

Figures 1 and 2 show relationship between body weight and egg production traits. Egg length, index, weight, albumen weight and shell weight rose between 1473 and $1626 \mathrm{~g}$ body weight, assumed undulating trend between 1626 and $1822 \mathrm{~g}$ body weight and finally declined between body weight range of 1822 and $1923 \mathrm{~g}$. The yolk weight dropped within the body weight range of 1473 and $1626 \mathrm{~g}$. There were no differences in the shell thickness in the body weight range of 1473 to $1650 \mathrm{~g}$. These findings showed no appreciable disagreement with Funk (1994), Briggs and Nordskog (1967) and Ayorinde et al. (1988) who reported that egg production traits changed with body weight.

Body weight was lowly, positively and nonsignificantly correlated with egg length, breadth, yolk weight, albumen weight and shell thickness $(P>0.05)$; significantly with egg weight $(<0.01)$ and negatively with egg index (Table 2). Similar correlated values for body weight and some production traits had been reported by Harms et al, (1982) and Ricklefs (1983).

There appeared to be a general direct relationship between body size and egg size. The positive significant correlation between body weight and egg weight was corroborated by Ayorinde et al. (1988) indicating egg weight increases with body weight contrary to 


\section{CHINEKE}

Singh (1990) who reported that decreased body size could lead to increased egg size. Nordskog (1960) reported positive correlation between body weight and egg weight and

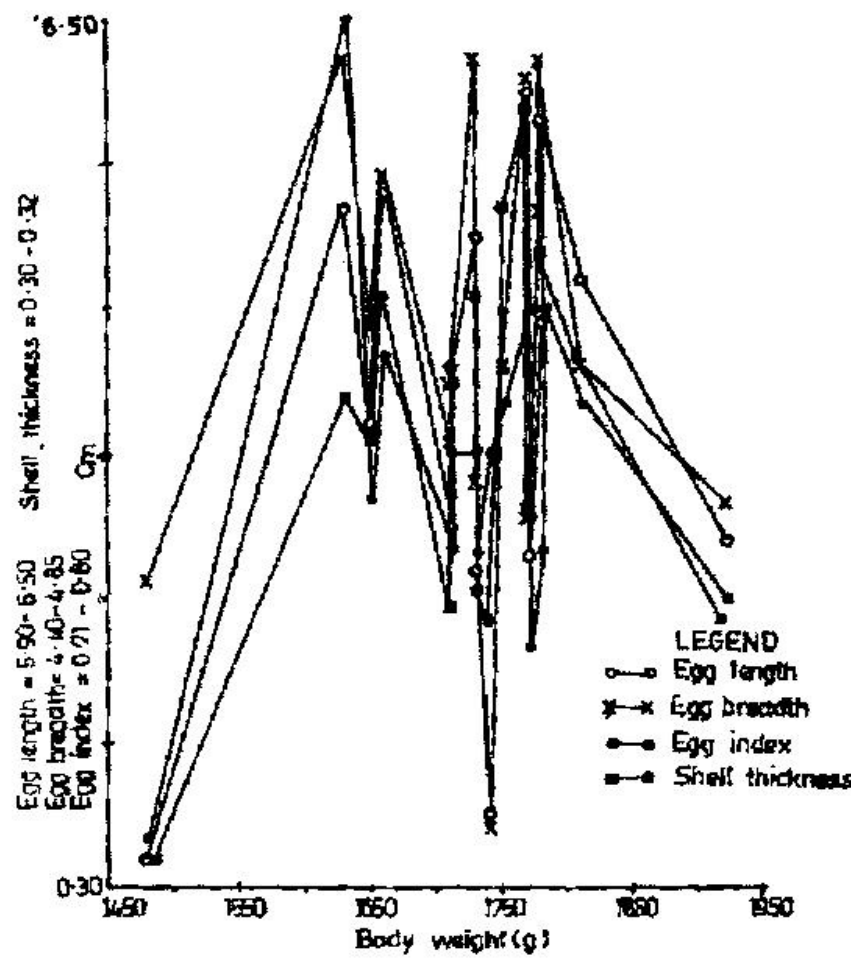

FIG 1: RELATIONSHIP BETWEEN WEIGHT AND EGG PRODUCTION TRATTS further pointed out that the rate of increase was not directly proportional to the increase in body weight.

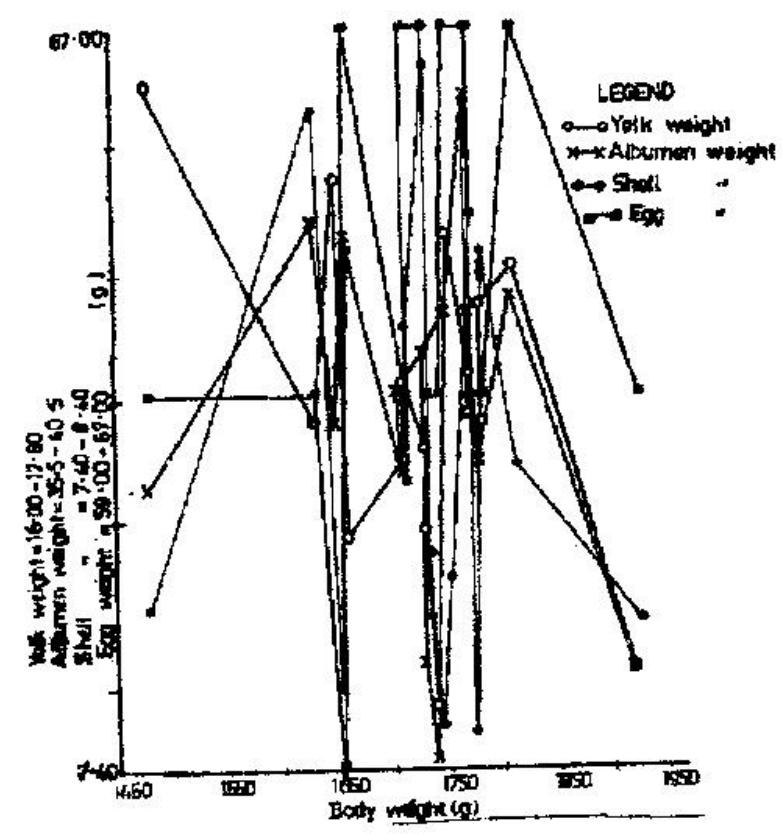

FIG 2: RELATIONSHIP BETWEEN WEJGHT AND EGG PRODUCTION TRATTS 
TABLE 2: $\quad$ MEAN SQUARES (MS) AND DEGREE OF FREEDOM (D.F.) FROM ANALYSES OF VARIANCE FOR EFFECT OF BODY WEIGHT ON VARIOUS EGG PRODUCTION TRAITS

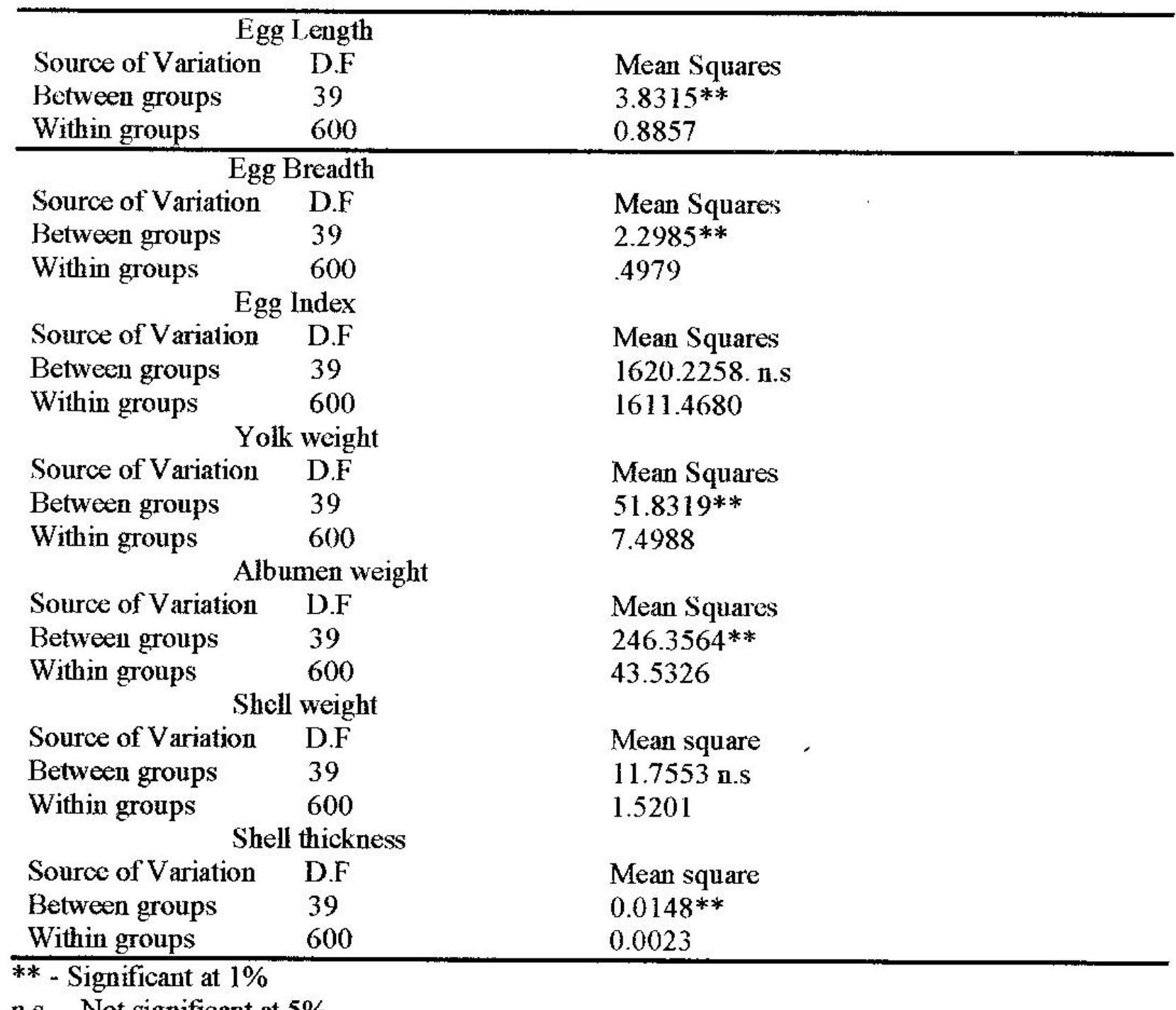

n.s. - Not significant at $5 \%$

The positive correlation coefficient for body weight and shell thickness obtained in the study, disagreed with Ayorinde et al. (1988) report that body weight was negatively correlated to shell thickness. Previously also, Nordskog (1960) and David (1980) observed that hens with small body sizes laid smaller sized eggs and irrespective of egg size, the amount of shell was the same. Ricklefs (1983) further pointed out that larger body size resulting in large egg length, width and mass could affect egg weight and that lighter body weight birds laid eggs with thinner shell.
However, a fixed amount of shell deposited on large eggs would tend to be thinner because the quantity of shell deposited either remained constant or increased slightly as the layer aged (Nwosu et al., 1987).

The positive correlated values for body weight and egg length and breadth (Table 3) agreed with Ricklefs (1983) findings that larger mature body size resulted in longer and broad eggs. The negative correlation between body weight and egg index might be attributed to the more positive response of egg breadth to 
TABLE 3: CORRELATION COEFFICIENTS, CONSTANTS AND MAXIMUM VALUES FOR EACH OF THE EGG TRAITS

CONSTANTS

\begin{tabular}{llllll} 
& & & & \\
\cline { 3 - 5 } Traits $(\mathrm{y})$ & $\mathrm{r}$ & $\mathrm{a}$ & $\mathrm{b}$ & $\mathrm{c}$ & Xmas. (kg) \\
\hline Egg length & $0.0847 \mathrm{n} . \mathrm{s}$ & 0.61480 & 6.61535 & -1.92142 & 1.721 \\
Egg breadth & $0.0846 \mathrm{n} . \mathrm{s}$ & 0.50293 & 4.91177 & -1.42482 & 1.724 \\
Egg index & $-0.0160 \mathrm{n} . \mathrm{s}$ & -4.10837 & 12.97252 & -5.10326 & 1.271 \\
Egg weight & $0.1243 * *$ & 1.61206 & 69.13729 & -19.19785 & 1.800 \\
Albumen weight & $0.0649 \mathrm{n} . \mathrm{s}$ & 4.05713 & 40.06824 & -11.70979 & 1.711 \\
Yolk weight & $0.0711 \mathrm{n} . \mathrm{s}$ & 2.11937 & 17.38652 & -5.05424 & 1.720 \\
Shell weight & $0.087 \mathrm{n} . \mathrm{s}$ & 0.65499 & 8.36932 & -2.40366 & 1.741 \\
Shell thickness & $0.0554 \mathrm{n} . \mathrm{s}$. & 0.04129 & 0.32732 & -0.09712 & 1.720 \\
\hline
\end{tabular}

$\mathrm{r}$-correlation coefficients

n.s. - Not significant at $5 \%$

** - Significant at $1 \%$

$\mathrm{a}, \mathrm{b}, \mathrm{c},-$ Constants for predicting $\mathrm{y}$ (egg traits) by substituting $\mathrm{X}$ (body weight into the regression equation $X \max$ - value of $x$ (body weight) for the maximum value of $y$ (egg traits) determined from $b / 2 c$.

changes in body weight than did egg length. This implies that as egg index decreases with an increase in body weight, the eggs will be more oblong in shape.

The correlation between body weight and egg production might be positive (Render et al., 1984) or negative (Nozchev and Kunev, 1973 and Harms et al., 1982) as observed by the named workers. Nordskog (1960) asserted that the negative association could be due to fat deposition in large bodied hen.

The association between body weight and different egg production traits in the study was non-linear. Such non-linearity might be related to a direct functional association between those variables or from the confounding of two or more simpler relationships, which though would be themselves linear. This was similar to the report of Ayorinde et al. (1988) that body weight and egg traits was non-linear. A significant quadratic relationship between total egg production and body weight at sexual maturity in the White Leghorn had been observed by Du plisses and Erasmus (1972).
The correlation coefficients; and constants in the equations for predicting 76 week body weight $(\mathrm{x})$ from the egg traits (y) are given in Table 3 . The equations indicate optimum body weight below or above which the different egg traits would decrease as $1.721,1.724,1.271$, $1.800,1.711,1.720,1.74 \mathrm{I}$ and $1.720 \mathrm{~kg}$ for egg length, breadth, index, weight, albumen weight, yolk weight, shell weight and sheil thickness respectively. These results suggest that maintaining the body weight range of 1.720 to $1.800 \mathrm{~kg}$ in Olympic Black Hens through breeding, good feeding and management practices will ensure satisfactory egg production, weight, shape and shell quality.

\section{REFERENCES}

ADENOWO, J.A., OMEJE, S.S.A. and DIM, N.I. (1995): Evaluation of pure and crossbred parent stock pullets: 1. Egg weight, Body weight and sexual maturity. Nig $\mathbf{J}$. Anim. Prod. 22:10-14.

ASUQUO, B.O. (1994): Some production parameters of Lohmann brown broiler parent lines in the humid Tropics. Nig. J. Anim. Prod. 21:1-4. 
AUSTIC, R.E. and NESHEIM, M.C. (1990): Poultry Production. Lea and Febiger, $13^{\text {th }}$ ed. London.

AYENI, J.S.O., TEWE, O.O. and AYAJI, S.S. (1983): Body measurements, egg characteristics and carcass composition of guinea fowl. Trop. Agric. (Trinidad) 60:224-226.

AYORINDE, K.I., ATTEH, J.O. and JOSEPII, K. (1994): Pre-and Post hatch growth of Nigerian indigenous guinea fowl as influenced by egg size and hatch weight. Nig. J. Anim. Prod. 15:59-65.

AYORINDE, K.L., TOYE, A.A. and ARULEBA, T.P. (1988): Association between body weight and some egg production traits in a strain of commercial layers. Nig. J. Anim. Prod. 21:119-125.

BRIGGS, D.M. and NORDSKOG (1967): Antagonistic selection for egg weight and body weight. Poultry Sci. 46 (5):1237.

DAVID, A.R. (1980): Egg shell quality (III). Effect of dietary manipulations of protein, amino acids, energy and calcium in young hens on egg weight, shell quality and egg production. Poult. Sci. 59:2047-2054.

DRAPER, G.H., KRUEGER, W.F. and QUISENBERRY, J.H. (1961): The relationship of dressing percentage to body measurements in turkeys. Poultry Sci. 40:1396.

DU PLESSIS, P.H.S, and ERASMUS, J. (1972): The relationship between egg production, egg weight and body weight in laying hens. World Poultry Sci. J. 28(2): 73.

EBANGI. A.L. and IBE, S.N. (1994): Heritabilities of and genetic correlations between some growth trails in Nigerian local chickens. Nig. J. Anim. Prod. 21:1924.

FUNK, E.G. (1994): The relationship of body weight of turkey hens to egg production, egg weight, percentage hatch and viability of poultry: Sci. 29(1):64-44.

GERSTMAYR, S. and HORST, R. (1990): The relationship between body, egg and oviduct weight in laying hens. J. Anim. Breed Genet. 107:149-158.
HARMS. R.II., COSTA, T.P. and MILES, R.D. (1982): Daily feed intake and performance of laying hens grouped according to body weight. Poultry Sci. 61(6): 1021.

LITTLE, T.M. and IIL.I.S, F.J. (1978): Agricultural Experimentation. Design and Analysis. John Wiley and Sons. New York.

MONSI, A. (1992): Appraisal of interrelationships among live measurements at different ages in meat-type chickens. Nig. J. Anim. Prod. 19:15-24

NORDSKOG. A.W. (1960): Importance of cgg size and other factors in determining net income in random samples test, Poultry Sci. 39: 327-338.

NO7,CHEV, S, and KUNEV. K. (1973): Correlation between cgg production and some production characteristics in White Leghorn hens. A.B.A. 41(7):367.

NWOSU, C.C., OMEJF, S.S.I. and LKEME, A.I. (1987): Effect of genotype, age and egg size on measures of shell quality of local and cross bred hens. J. Anim. Prod. Res. 7(1):19-27.

OLORI, V.E. and SONAIYA, E.B. (1992): Effect of length of lay of Nigerian indigenous chickens on their egg composition and shell quality. Nig. J. Anim. Prod. 19:95-100.

OMEJE, S.S.I and NWOSU, C.C. (1984): Mode of inheritance and interrelationship of age and body weight at first cgg and other short-term production parameters in local and exotic cross bred chicken. Prod. $17^{\text {th }}$ World's Poultry Congress. Helsinki. Finland Vol. 13, 9:791-793.

ONI, O.O., ABUBAKAR, B.Y. and OGUNDIPE, S.O. (1991): Genetic and phenotypic associations of jurenile body weights and egg production traits in two strains of Rhode Island chickens. Nig. J. Anim. Prod. 18:66-70.

RENDER, J.A.. MCDANIEI, G.R. and MCQUIRE, J.A. (1984): Egg characteristics and production efficiency of dwarf white leghorn hens divergently selected for body weight. Poultry Sci. 63(2):214. 


\section{CHINEKE}

RICKLEFS, R.E. (1983): Egg characteristics of lines of Japanese quails selected for 4 weeks body mass. Poultry Sci. 63:1330.

SINGH, R.A. (1990): Poultry production. Kalyani Pub. New Delhi-Ludhiana. 239241.

SNEDECOR, G.W. and COCHRAN, W.G. (1973): Statistical Methods The lowa University Press Ames, Iowa, U.S.A.

SPSS (1986): Statistical Package for social science procedures and facilities for release. MCGRAW-HILL Book Co. New York.

STEEL, R.G.D. and TORRIE, J.H. (1980): Principles and procedures of statistics. A Biometrical Approach. Second edition MC GRAW-Hill Book Coy. Inc. New York.

YOUNGER, M.S. (1985): A first course in Linear regression Second Edition. The University of Tennessee, Prindle, Weber and Schmidt, Duxbury Press, Boston. 